\title{
Eugenio Barba: memória e resistência no teatro
}

Andrea Copeliovitch*

RESUMO: Este texto é uma introdução ao pensamento de Eugenio Barba acerca de seu fazer teatral, um teatro criativo e auto-criador. Mas é também um agradecimento à generosidade desse mestre; generosidade que pude vivenciar em alguns encontros e que está na base de seu projeto de um teatro que prevê comunhão e trocas; um teatro efêmero como a vida, mas tão vivo e intenso como ela pode ser. PALAVRAS-CHAVE: Eugenio Barba, Odin Teatret, técnica do ator, ética e teatro.

ABSTRACT: This text is an introduction to Eugenio Barba's thought about his theatrical practice, a creative and self-creator theatre. But it is also in gratitude to this master's generosity; generosity that I could experience in some meetings and that is the basis of his theatre project that envisions communion and exchanges; An ephemeral theatre like life, but as alive and intense as it can be.

KEYWORDS: Eugenio Barba, Odin Teatret, actor technique, ethics and theatre.

\footnotetext{
* Andrea Copeliovitch é atriz, bailarina, doutora em Poética pela Universidade Federal do Rio de Janeiro (2005) e tem Pós-Doutorado pelo CEAQ (Université de Paris V, Sorbonne). Atualmente é professora associada da Universidade Federal Fluminense (Dança e performance). Dirigiu a companhia Gaya Dança Contemporânea de 2006 a 2008 e atualmente dirige e coordena o projeto "Ação e linguagem na cena".Tem experiência na área de Artes, com ênfase em Interpretação Teatral, atuando principalmente nos seguintes temas: dança, ator, teatro, linguagem e ritual.
} 
Ele não tinha ido a nenhuma parte. Só executava a invenção de se permanecer naqueles espaços do rio, de meio a meio, sempre dentro da canoa, para dela não saltar, nunca mais. A estranheza dessa verdade deu para estarrecer de todo a gente. Aquilo que não havia,

acontecia.

João Guimarães Rosa. "A terceira margem do rio".

De onde vem a linguagem? Como se deu esse ato de codificação, quando um homem decidiu designar tal coisa por tal nome e tal ato por tal verbo? A origem parece ter desaparecido em algum ponto mítico do tempo, as tradições de transmissão muitas imemoriáveis já perderam a necessidade de retornar a um princípio mais do que a uma origem. O princípio se refere a um ponto histórico da nos cronologia, enquanto a origem é o manancial das águas, de onde flui outra linguagem que se dá em um tempo difuso, Kairós. Provavelmente é essa linguagem que perseguimos enquanto atores.

Os gregos utilizavam uma mesma palavra, séma, para designar "túmulo" e "signo". Na linguagem de outros povos também podemos encontrar uma identificação parecida. As doutrinas, os métodos e as poéticas são os túmulos e os signos dos homens que, no passado, se aventuraram por novos caminhos. Podemos olhá-los como monumentos que se deixam admirar, comentar e imitar. Ou então podemos olhá-los para descobrir, além daquele signo, o sentido de uma vida que descobriu o seu caminho e o percorreu. (BARBA, 2010, p.203)

Eugenio Barba, grande mestre pedagogo e diretor de teatro, usa o termo "princípios que retornam" para falar com os atores. Na linguagem oral os princípios retornaram e se tornaram língua, depois representação pictórica, escrita e, em algum momento, fonética. O retorno dos princípios e sua fixação escrita oferecem ao homem um respiro ilusório no reino da permanência.

Na época de Platão houve uma popularização da escrita na Grécia, cujo conhecimento era transmitido oralmente, de geração em geração, de professor para aluno, de mestre para discípulo (HAVELOCK,1996). Esse conhecimento oral não presumia uma verdade absoluta, era fluido como o rio de Heráclito em cujas águas não podemos nos banhar duas vezes e passou a ser usado como ferramenta na mão dos sofistas que faziam propaganda política. 
Platão tenta se opor a essa distorção e propõe para o imaginário ocidental a ideia de uma verdade absoluta, de um mundo das ideias cuja perfeição é apenas representada em nosso "insuficiente" mundo sensível.

O estabelecimento de uma verdade absoluta não coincidentemente acontece no momento em que o conhecimento escrito passa a prevalecer sobre o conhecimento oral. A representação de uma verdade absoluta através de signos fonéticos nos dá a ilusão de permanência: o que está escrito permanece, vira lei e nos traz uma rigidez de conceitos e ideias, "signos como túmulos" que nos acompanham até hoje. "O ator se transforma então no grande provocador. Encarna o paradoxo: age no presente dirigindo-se a espectadores que foram ou que serão, e não ouve os aplausos de seu tempo" (BARBA, 2010, p.105).

O teatro é por princípio impermanência, se dá no aqui e agora, na efemeridade do espetáculo. Desde o mestre russo Konstantin Stanislávski há uma busca pelo estabelecimento de uma linguagem no teatro ocidental ou do teatro ocidental. Aqui usamos ocidental como uma categorização exclusivamente didática, já que a Rússia, geograficamente eurasiana, fica no limiar do ocidente e do oriente, assim como o teatro fica no limiar das linguagens: canto, dança, oralidade, mímica. O ator é o mensageiro e a mensagem, desenvolve em si a própria linguagem. Essa é a busca dos grandes mestres de teatro que marcaram o século XX e que no caso de Barba continua marcando o século XXI.

Aos dezoito anos passei uma noite acampada no deserto do Neguev. Sob a imensidão do céu deixei de sentir a minha própria separação. O céu estrelado dava a impressão de infinito, e eu, deitada sobre a areia também incontável, não podia distinguir o meu eu dos grãos de areia, nem das formigas, nem das estrelas. Eu era nada e ao mesmo tempo infinita, misturada ao todo em uma sensação de plenitude que tenho buscado repetir ao longo da minha vida.

Em seu livro The Sleepwalkers, dedicado à história das mudanças visão do homem sobre o universo, Arthur Koestler mostra como todo ato criativo - na ciência, na arte ou na religião - é realizado através de uma regressão preliminar a um nível mais primitivo: reculer pour mieux sauter. É um processo de negação ou de desintegração que prepara para o salto, para o resultado. Koestler chama esse momento de uma pré-condição criativa.

Queimar a casa. (BARBA, 2014, p. 131)

Quem primeiro queimou a minha casa foi Luiz Otávio Burnier. 
Começo essa história com fatos de quase 30 anos atrás quando minha colega de quarto me inscreveu em um trabalho intensivo com Luiz Otávio Burnier. Burnier era nosso professor de Dança, música e ritmo no curso de Artes Cênicas da Unicamp. Suas aulas eram muito duras e estavam longe de ser as minhas favoritas. O trabalho intensivo começava às 05h30minh da manhã e ia até as 13h, de segunda a sábado. Eu fui pelo simples fato de ter medo do Burnier.

Quando fui estudar teatro, entendia esse ofício como muitos, a partir do texto. Gostava de encarnar uma personagem, de improvisar, fazer comédia, mas o dado concreto era o texto. Na faculdade, a ideia de improvisar já começava a se ampliar. Podíamos improvisar sobre um tema, um objeto, e para isso precisávamos desconstruir nossos (pré) conceitos sobre o tema e sobre o objeto. Esse exercício se dava sempre de forma lúdica, e ao final, que costumava ser a apresentação da cena resultante do improviso, sempre me sentia criativa. Burnier me fez vislumbrar a possibilidade de queimar a casa, de acabar com meu próprio eu tal qual o conhecia e de forma que eu jamais me atreveria sozinha, no final de suas aulas não havia um improviso criativo mas a repetição de sequências de movimentos realizados durante os exercícios (nessa época eu não sabia distinguir ação de movimento). Eu, recém-saída da adolescência, me rebelava contra o rigor do treinamento e sua aparente falta de resultados. Essa maneira de trabalhar presumia dor, perigo, insegurança, desconhecimento. Barba fala sobre essa destruição do conhecido como base da nossa preparação enquanto atores:

É um momento que parece negar tudo o que caracteriza a busca do resultado. Não determina uma nova orientação, é mais uma desorientação voluntária que obriga a movimentar todas as energias do pesquisador, afinando seus sentidos, da mesma forma em que se penetra na obscuridade. Essa dilatação das próprias potencialidades tem um preço alto: perde-se o domínio do significado da própria ação. É um negar que ainda não descobriu o novo que afirma. (BARBA, 2014, p.131)

É esse nível de negação que propõe o trabalho desses mestres - Luiz Otávio Burnier, Jerzy Grotowski, Eugenio Barba - trabalho que parte de uma destruição, de um salto para o nada, sem garantias de que haverá uma cena final, um resultado que nos faça criativos e realizados como atores, ou muitas vezes o resultado sai de nosso controle e nas mãos do diretor assume uma forma completamente inesperada.

A prática com Burnier começava com a limpeza do espaço e o silêncio. Não podíamos conversar enquanto estivéssemos no trabalho. Não dávamos "bom dia" quando chegávamos à sala. 
Cada um ia para o seu quadrado, limpava-o e começava a trabalhar. Primeiro, praticávamos exercícios extremamente técnicos como enraizamento, decupagem do corpo e o trabalho com o bastão e com o pano.

Trabalho com objetos - trabalhamos em nossos treinos basicamente dois tipos de objetos: 0 bastão e o tecido. Um, rígido, de forma fixa e imutável, e o outro, flexível, cuja forma é mutável. Para o treinamento com o objeto, é importante desenvolver a escuta de sua dinâmica. Cada objeto tem uma forma, uma espessura, um peso que determinam uma dinâmica muito particular se lançado no ar. Este treinamento visa desenvolver uma relação ator-objeto onde os impulsos das ações do ator são transferidos para o objeto, e a dinâmica espacial do objeto é transferida para o corpo do ator. Este trabalho começa com o enraizamento do corpo, depois inicia-se um contato com o objeto, sua forma, peso, textura, depois um aprendizado de manipulações técnicas possíveis, uma relação dinâmica ator-objeto-ator, e por fim a transformação do objeto. Por "transformação do objeto" quero dizer o momento quando este toma outro sentido e significado para o ator. (BURNIER, 1994, p.153)

Depois, tentávamos fixar sequências a partir de nossas próprias descobertas. Assim, íamos desenvolvendo, cada um de nós, uma técnica própria. A ideia era superar os próprios limites, e não superar os limites do outro. Luiz pedia a cada um de nós que trouxesse um paninho para que, se acaso vomitássemos, limpássemos nosso próprio espaço, pois muitos de nós vomitávamos de cansaço, de estresse. Não podíamos parar. Havia dias em que podíamos ir ao banheiro e outros não.

Ao fim do primeiro dia, eu já estava decidida a não voltar e pensei: “bom, vou amanhã só para comunicar que não vou mais, por algum motivo". E no dia seguinte, ainda escuro, estava andando a pé para a Unicamp, quando passou um fusca e buzinou: era o carro de Luiz Otávio. Ele falou: "Você mora aqui por perto?" Eu disse que sim e ele se ofereceu para me levar todos os dias para o trabalho. Assim, eu fui obrigada a ficar. Mal sabia eu, aos vinte anos de idade, que aqueles quinze dias mudariam toda a minha vida, toda a minha história com o teatro. De fato, todas as perguntas que eu tenho, que eu persigo até hoje, vêm daquele período. Em primeiro lugar, o silêncio descoberto na madrugada. Às cinco e meia da manhã, não existe barulho: apenas o cantar de um galo. E era nesse silêncio que começava o nosso trabalho, era nesse silêncio que começávamos a nos descobrir enquanto seres humanos, enquanto jovens atores, enquanto trabalhadores do teatro. Limpávamos o nosso chão, limpávamos o nosso 
espaço, limpávamos a nossa mente, limpávamos os nossos gestos conhecidos, os nossos mecanicismos, os nossos vícios de atores que, mesmo jovens, já possuíamos.

Buscávamos desenvolver o que Burnier chamava de Dança pessoal, entendendo esta dança como "a dinamização de energias originárias e primitivas do ator (que se encontram normalmente adormecidas) por meio de ações físicas" (BURNIER, 1994, p. 165).

E intentávamos compreender em nossos corpos a "ação física", expressão cunhada por Konstantin Stanislávski e que norteia e desestabiliza o caminho do ator desde os primórdios do século XX. Para Barba (1994, p.221): “É necessário definir a ação de maneira functional para que possa nos servir no trabalho quotidiano. Entendemos por ação aquilo que me muda e que muda a percepção que o espectador tem de mim." A ação física é nossa matéria-prima, construímos/confeccionamos nosso trabalho como faz um músico com a nota à composição final. Stanislávski também designou esse processo por partitura. De acordo com Eugenio Barba:

\footnotetext{
A ação do ator é real se está disciplinada por uma partitura. O termo partitura (utilizado pela primeira vez por Stanislávski e retomado por Grotowski) indica uma coerência orgânica. É em virtude de tal coerência orgânica que o trabalho sobre o pré-expressivo pode ser conduzido como se fosse independente do trabalho sobre o sentido (do trabalho dramatúrgico), e pode orientar-se segundo seus próprios princípios conduzindo à descoberta de significados não óbvios, instaurando a dialética do processo criativo entre organização e casualidade. (BARBA, 1994, p.174)
}

O que eu entendia por sequência de movimentos necessitava de um salto qualitativo para tornar-se partitura de ações físicas.

Em alguns dias de trabalho, fatos aconteceram com o meu corpo, com a minha mente, que eram indescritíveis, que nunca haviam acontecido antes. O trabalho com o bastão não era realizado na sala, mas sim no Observatório a olho nu, que era um espaço amplo da Unicamp, fora do perímetro do Departamento de Artes. Começávamos assim: passávamos o peso do bastão de um lado para o outro e íamos dificultando essa passagem de peso, desafiando as nossas próprias habilidades. Pegávamos mais na ponta do bastão, atirávamos mais longe, deixávamos cair no chão para pegar em seguida, até que, em um determinado momento, meu corpo e o bastão se tornaram o mesmo, e era impressionante, essa comunhão ampliava-se para o espaço, era preciso ser um com o bastão, com cimento e com a vastidão do céu. 
Lembro-me uma vez, também, de ter visto o trabalho de Ricardo Puccetti com seu bastão, em que ele girava o bastão no ar para cima, todo seu ser tinha se tornado um helicóptero e parecia uma coisa impossível de se fazer, e, no entanto, era perceptível que era exatamente isso: o corpo dele e o bastão eram exatamente a mesma coisa. Aquilo começava a me dar pistas de que esse ofício exigia uma diluição do eu, uma não separação do eu e do outro, seja o outro um bastão, o espectador ou o próprio chão sobre o qual trabalhávamos e sobre o qual praticávamos o exercício de enraizamento até doerem os joelhos, até os pés sangrarem.

Eu comecei a entender que o rigor daquele trabalho era fundamental, que era impossível conseguir alguma coisa sem trabalhar todos os dias, sem desafiar a preguiça, sem desafiar os limites do corpo.

Foi mais ou menos nessa época que encontrei Eugenio Barba pela primeira vez. Ele veio algumas vezes ao nosso pequeno departamento na Unicamp, conversava conosco e também seus atores faziam demonstrações técnicas nos teatros da cidade. Lembro-me da primeira demonstração a que assisti da atriz Julia Varley, cuja voz parecia sair de lugares inimagináveis, como se já não pertencesse ao seu corpo, mas se expandisse através de linhas invisíveis no tempo e no espaço para atingir diretamente a mim, espectadora, sem a necessidade da lógica dramatúrgica, da cronologia aristotélica. Essa primeira demonstração foi como um fio de Ariadne lançado sobre o labirinto de práticas no qual Luiz Otávio Burnier me havia iniciado. Julia Varley fala sobre essa função didática da demonstração técnica:

Desde sempre, ensinar obrigava-me a aprender, e a responsabilidade de organizar coisas para outras pessoas fortalecia o meu ofício.

Ao longo dos anos, o problema a ser resolvido estava na quantidade de pessoas que queriam participar de nossos seminários. As demonstrações têm sido uma das maneiras de atender às demandas de formação cada vez mais numerosas e de relatar o processo de trabalho do Odin Teatret àqueles que não têm a oportunidade de nos encontrar na prática. (VARLEY, 2016 p.229)

Demonstração técnica é talvez a negação da tal cena final, resultado da aula de improvisação ou interpretação. A demonstração técnica vem da persistência desses atores no salto para o nada, no rigor com que adquirem a capacidade de repetir os impulsos que os levaram a saltar e que Ihes permitiram aterrissar. 
Em suas visitas a Campinas, Barba falava muito em técnica do ator e parecia que estávamos escutando o mesmo discurso de Burnier, que tanto havia me incomodado no começo. Com o tempo a palavra técnica passou a fazer parte do meu corpo, do meu dia a dia, e, quando segui a vida acadêmica, também dos meus textos. No doutorado meus professores de filosofia criticavam muito o meu uso dessa palavra, essa palavra tão fluida nos lábios e letras de Eugenio Barba, nos meus, saía dura e desajeitada. Eu insistia que a técnica era essencial para o ator, sem então compreender que para Barba essa palavra não se dissocia de ética e subjetividade, e que é bem provável que o que ele chama de teatro seja o equivalente àquela noite estrelada no deserto.

No início das nossas atividades, nós também acreditávamos no "mito da técnica", algo possível de conquistar, de possuir, e que teria permitido ao ator dominar, dirigir o próprio corpo, se tornar consciente dele (BARBA in BARBA \& SAVARESE, 2012, p.288). Barba reflete sobre o "mito da técnica" em seu texto sobre o treinamento no Dicionário de Antropologia Teatral. Partindo de sua experiência com o Kathakali ele questiona que talvez esse controle facial "em um ator europeu, acabaria bloqueando as reações orgânicas do rosto, transformando-o numa máscara sem vida" (BARBA in BARBA \& SAVARESE, 2012, p.288). A questão da técnica para Barba começa com uma busca muito concreta de praticar com seus atores o que ele havia aprendido.

Quando olho ao meu redor e tento entender no que se transformou a busca teatral dos anos de 1960, vejo com clareza que ela foi se dirigindo aos poucos para uma direção que, no começo, nenhum de nós estava prevendo. Um vínculo profundo com uma história bem precisa, cujos antepassados podiam ser Stanislávski, Meyerhold ou Brecht, nos levava a traduzir nossas necessidades em termos de teatro, de "reforma da linguagem teatral", de seus meios expressivos. Mas com o tempo e a experiência, esse vínculo foi mais além da profissão, tornou-se atitude ética, com um modo próprio e diferente de perceber, de agir. Se para várias pessoas essa atitude representa uma ampliação das fronteiras do teatro, muitas vezes ela nos parece uma recusa de tudo aquilo que, na nossa cultura, tem sentido chamar de teatro. (BARBA, 2010, p.209)

Começaremos nossa reflexão sobre esse fugidio tema da técnica/ética a partir de minhas anotações feitas nas residências artísticas com Eugenio Barba e Julia Varley promovidas pela diretora Luciana Martuchelli das quais participei, em Brasília, nos anos de 2014, 2015 e 2016 ("Como pensar através de ações VII, VIII e IX"). 
Eugenio Barba começa sua carreira como diretor convidando atores rejeitados pelo conservatório de teatro em Oslo. Trabalhavam então em uma sala de escola à noite. Vindo dos anos de aprendizado com Jerzy Grotowski, Barba já não tinha uma visão de teatro convencional no sentido da espacialidade. Grotowski coloca o espectador no centro de forma que ele perde a orientação de sua percepção, pois tem de escolher em que focar a sua atenção. Barba fala que trabalhar na escola favoreceu um tipo de relação, de técnica, onde treinamento equivale a aprendizagem. Essa técnica de ator não é óbvia, não é um aprendizado estruturado como o de um bailarino de balé clássico ou de Kathakali, ou de um ator Nô; ela acolhe elementos dessas e de outras técnicas em busca de uma técnica individual, única, intransferível e ao mesmo tempo, aprendida com um mestre.

Ainda falando sobre o início de sua carreira como diretor, Barba conta da dificuldade com a língua. Ele saiu da Itália aos dezoito anos, foi para a Noruega, depois para a Polônia, voltou para a Noruega e depois se estabeleceu na Dinamarca. "A experiência no idioma estrangeiro não é imediata como a reação emocional quando se escuta o idioma de sua mãe. Eu falo todos os idiomas perfeitamente como se estivesse fora de ritmo", revelou Eugenio Barba em "Como pensar através de ações IX".

Nós atores ocidentais contemporâneos não falamos nenhum idioma, o ator de teatro Nô fala um idioma concreto. Nessa torre de Babel do nosso teatro, como nos fazer entender? Antes de Stanislávski, acreditava-se que o texto era suficiente, mas o mestre russo aboliu essa tranquilidade. Precisamos determinar as ações físicas, criar uma partitura, ou, segundo Barba, determinar impulsos precisos. "Se o ator trabalha com impulsos precisos, uma boa parte dos espectadores vai entender. (Esse ator) desenvolve um outro tipo de comunicação que funciona em nível orgânico" (Fala de Eugenio Barba em "Como pensar através de ações IX"). O que são esses impulsos e como torná-los precisos?

Seguramente os impulsos pertencem ao reino do que Stanislávski chama de organicidade. Segundo Barba, Stanislávski coloca tudo isso num microscópio para produzir no espectador a sensação de vida. O espectador pode crer ou não crer no que está assistindo. Convencer o espectador em um nível primário é precisão, é fazer o que é necessário. Sobre o que é necessário, Barba fala o seguinte, no texto "Um teatro feito sem regras e tijolos", do livro $A$ canoa de papel: 
Em nível pré-expressivo não existe a polaridade realismo/não realismo, não existem ações naturais ou não naturais, mas apenas gesticulações inúteis ou ações necessárias. "Necessária" é a ação que compromete o corpo todo, que muda perceptivelmente a sua tonicidade, que implica um salto de energia mesmo na imobilidade. (BARBA, 1994, p.165).

Barba estabelece uma série de termos para falar para o ator: equilíbrio precário, oposições, sats, koshi.

Oposições são a base do trabalho do ator, como o chiaroscuro na pintura, como som e silêncio na música, pausa e movimento, toda linguagem poética não é afirmativa e acolhe os opostos. Barba detecta a necessidade de perceber e enfatizar essas oposições, o ator treina possibilidades de oposições, encontra o equilíbrio/desequilíbrio e põe-se em equilíbrio precário; na oposição entre andar e não andar, aprende com mestres do Nô e Kabuki o koshi como energia e presença. No final dos anos 1980, começo dos 1990, praticávamos com Luiz Otávio Burnier o exercício descrito por Barba no Dicionário de Antropologia Teatral (BARBA \& SAVARESE, 2012) de segurar outro ator pela cintura, impedindo-o de se deslocar na busca do tal koshi. Ainda recorremos ao Dicionário de Antropologia Teatral para investigar o termo sats: "O termo sats do Odin Teatret, ou seja, o impulso para a ação - que através do não movimento é energia no tempo - era definido por Stanislávski como 'estar no ritmo certo'" (BARBA \& SAVARESE, 2012, p.91).

Para explicar o ritmo certo proposto por Stanislávski, Barba e Savarese (2012, p.91) citam um exemplo do ator Toporkov (2016), que trabalhou com Stanislávski entre os anos de 1927 e 1938, a respeito de sua dificuldade com o tempo-ritmo como elemento do "sistema" de Stanislávski, quando este quis que ele golpeasse um rato com um bastão e ao mesmo tempo batesse palmas. Toporkov só poderia encontrar o momento certo do golpe se compreendesse o impulso, o princípio do impulso (sats), e alcançasse a precisão de sua execução. Stanislávski aponta para seu pupilo a diferença entre esperar para golpear um rato ou um tigre. Essa diferença determina ritmo e impulsos distintos. A precisão de sua execução depende de trabalho árduo, repetição, concentração, imaginação, escuta e capacidade de jogar - interagir com o outro, nisso consiste a técnica do ator.

Essa interação com o outro, se pensarmos no Odin Teatret se amplia para o que Eugenio Barba denominou "terceiro teatro," o qual é definido "exatamente pela ausência de um sentido 
comum. Ele é o conjunto de todos aqueles teatros que constroem um sentido para si mesmos, ou seja, cada um deles define, de forma autônoma, um sentido pessoal da ação de fazer teatro" (BARBA, 2010, p.250).

Nós atores, marginais em essência, terceiro mundo do mundo, terceira classe da vida, terceira margem do rio, saímos a cada dia em busca de uma expressão, de uma ação, de uma linguagem; adentramos o tempo do não ser, do deixar de ser, do desmascarar.

Eugenio Barba, esse grande mestre, nos presenteia com ações e palavras, ações do "como fazer" esse ofício sem sentido e pleno de sentido que é o teatro; palavras para falar do ofício, das dificuldades, dos acertos, da repetição e da busca da vida naquilo que fazemos.

Essa vida que buscamos no teatro se enche de sentido nos encontros: com o público, com o diretor, com os outros atores, com o texto, com o personagem, com os grandes mestres, com nós mesmos... Grotowski já havia dito: "Teatro é encontro". Eugenio Barba e o Odin Teatret nos mostram como é possível que um encontro se torne resistência e permanência na efemeridade da vida refletida no teatro; na efemeridade da vida refletida no pequeno cemitério na sede do Odin em Holstebro, Dinamarca. O terceiro teatro é encontro de subversores, de resilientes atores.

A grandiosidade do Odin Teatret está em não se isolar no Valhalla daqueles que atingiram o tão sonhado sucesso, mas em permanecer em vida, em busca e em contato.

Agradeço cada um de nossos encontros e cada doação recebida.

\section{Referências}

BARBA, Eugenio. Teatro - solidão, ofício, revolta. Brasília: Teatro Caleidoscópio, 2010. . Queimar a casa: origens de um diretor. São Paulo: Perspectiva, 2014. . A canoa de papel: tratado de antropologia teatral. São Paulo: Hucitec, 1994. ; SAVARESE, Nicola. A arte secreta do ator: um dicionário de antropologia teatral. São Paulo: É realizações, 2012.

BURNIER, Luiz Otávio. Arte do ator: da técnica à representação, elaboração, codificação e sistematização de técnicas corpóreas e vocais de representação para o ator. Tese de doutorado. PUC- São Paulo. 1994. 
HAVELOCK, Eric. Prefácio a Platão. São Paulo: Papirus, 1996.

ROSA, João Guimarães. "A terceira margem do rio". In: . Ficção completa: volume II. Rio de Janeiro: Nova Aguilar, 1994, p. 409-413.

TOPORKOV, Vassíli. Stanislávski ensaia: memórias. São Paulo: É realizações, 2016.

VARLEY. Julia. Uma atriz e suas personagens. Histórias submersas do Odin Teatret. São Paulo: É realizações, 2016. 